\title{
PERFIL PROFISSIONAL E PRÁTICAS DE DOCÊNCIA NOS CURSOS DE ADMINISTRAÇÃO: POR ONDE ANDAM AS NOVAS TECNOLOGIAS DO ENSINO SUPERIOR?
}

\section{PROFESSIONAL PROFILE AND PRACTICAL OF TEACHING IN THE ADMINISTRATION COURSES: FOR WHERE THEY WALK THE NEW TECHNOLOGIES OF SUPERIOR EDUCATION?}

\section{ANTÔNIO JOÃO HOCAYEN-DA-SILVA}

Mestre em Administração pela Universidade Federal do Paraná (UFPR).

Professor da Faculdade de Ensino Superior do Centro do Paraná. Avenida Universitária, S/N, Centro - Pitanga - PR - CEP 85200-000 E-mail:hocayen@yahoo.com.br MARCOS DE CASTRO Mestre em Administração pela Universidade Federal do Paraná (UFPR).

Professor da Universidade Estadual do Centro-Oeste (Unicentro). Rua Luis Cúnico, 1.345, Vila Bela - Guarapuava - PR - CEP 85027-030 E-mail: marcosdecastroms@yahoo.com.br

\section{CRISTIANO DE OLIVEIRA MACIEL}

Mestre em Administração pela Universidade Federal do Paraná (UFPR). Professor de Ensino Superior do Grupo Educacional Uninter/Faculdade OPET.

Rua Victor-Hugo, 131, Guaíra - Curitiba - PR - CEP 81010-130 E-mail: crmaciel.adm@gmail.com 


\section{RESUMO}

Com base em uma investigação com os docentes do curso de administração, a presente pesquisa busca evidenciar prováveis relações entre o perfil profissional dos pesquisados e suas práticas de docência, mais especificamente as tecnologias de ensino e avaliação. Essas relações foram exploradas por meio de um levantamento com cerca de 200 docentes. $\mathrm{O}$ artigo inicia com breve panorama da atual realidade do curso de administração no País. Na seqüência são discutidos o perfil dos docentes em administração, suas práticas de docência e as implicações desses elementos na qualidade do ensino em administração. Após as explanações iniciais, são apresentadas as análises dos dados e os resultados da pesquisa. Com o uso de estatísticas descritivas realizou-se a perfilação dos especialistas, mestres e doutores e a descrição das práticas de ensino e avaliação. Para o teste de diferenças das proporções foi realizado o teste Qui Quadrado. Por fim, o artigo encerra com as considerações finais à luz dos achados empíricos do estudo, tecendo apontamentos mais gerais no que concerne à questão da qualidade do ensino superior na área de administração.

\section{PALAVRAS-CHAVE}

Perfil; Práticas de docência; Novas tecnologias de Ensino; Cursos de administração; Educação superior.

\section{ABSTRACT}

Based on an inquiry with faculty members of business administration programs, the present research attempts to suggest the likely relations between the professional profile of the interviewees with their current lecturing practices, more specifically the teaching and evaluation technologies. These relationships were explored through a survey with circa two hundred faculty members. The paper begins with a brief overview of the business administration programs' 
current situation in Brazil. Then, the profiles of faculty members are presented followed by their lecturing practices and the consequential implications of such elements in the quality of business teaching. After these introductory explanations, the results of the survey and the analysis of the data is presented. With the help of descriptive statistics, a profiling of the specialists, masters and doctorates was made together with the description of the lecturing and evaluation practices. For the "test of proportion differences" the Chi-square test was performed. Finally, the paper concludes with final considerations based on the empirical findings, suggesting general guidelines regarding the quality of business administration teaching at college level.

\section{KEYWORDS}

Profile; Practical of teaching; New technologies of education; Administration courses; Superior education.

\section{INTRODUÇÃO}

O início do ensino superior na área de administração data da metade do século passado no contexto nacional (MOTTA, I983). Desde então, a realidade social no interior das organizações e suas relações com as diversas constituências $^{\mathrm{I}}$ do seu ambiente externo vêm, marcadamente, assumindo maior complexidade e importância e, por conseqüência, implicando maiores desafios à gestão dos sistemas organizacionais. Nicolini (2003) estabelece que, desde o seu início, o ensino de administração foi caracterizado pela transferência de tecnologia norte-americana e pelo distanciamento entre as atividades de ensino e pesquisa.

Nas últimas décadas esse cenário tem-se reconfigurado, entretanto outras mudanças mais recentes estão em foco, como o acentuado processo de expansão. Nesse sentido, vale considerar que o movimento de expansão do ensino superior não é resultado de estrito oportunismo dos agentes de mercado, e sim faz parte da reflexão de membros de diversas entidades ligadas à educação no País e no mundo. Um exemplo desse movimento é a promulgação da nova Lei de Diretrizes e Bases da Educação Nacional (LDB) em 20 de dezembro de I996, que veio iniciar novo processo de discussão do ensino superior. Pelo

Constituências, neste caso, são entendidas como todos os elementos ambientais que exercem o papel de audiência institucional. 
Parecer n⿳0 776/97, o Conselho Nacional de Educação torna a estimular as áreas a formular as diretrizes curriculares específicas para cada curso de graduação. Indo além, as comissões da Unesco foram responsáveis pela Declaração Mundial para o Ensino Superior no Século 2I, apresentada no ano de I998 em Paris. O encontro que deu origem a esse documento definiu diversos artigos de maior urgência, entre eles a expansão do acesso à educação superior, avaliação da qualidade e o financiamento da educação superior.

Apesar da origem da LDB e Declaração Mundial para o ensino superior datarem de 1996 e I998, respectivamente, foi só a partir de 2003 que essas reflexões passaram a ser debatidas em âmbito nacional. A partir daí deu-se início à sedimentação do processo de reforma da universidade no País, que desencadeou o súbito e contínuo aumento do número de instituições de ensino superior (IES). Uma representação do crescimento do número geral das IES públicas e privadas no Brasil aparece na Tabela I.

\section{TABELA I}

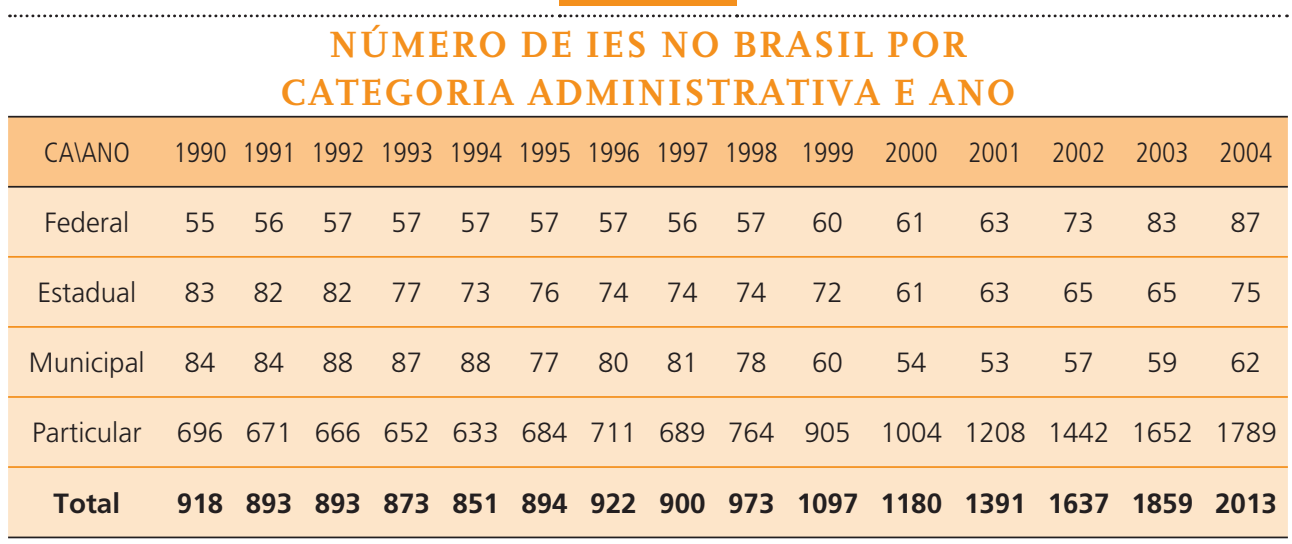

Fonte: Elaborada pelos autores a partir dos dados do Inep (2006).

Mais especificamente no âmbito das escolas de administração, a preparação de egressos para enfrentar uma maior complexidade social e a busca pelo desenvolvimento do ensino superior, como um todo no País, têm figurado como as principais razões para a constante preocupação com a capacitação dos docentes.

É fato que a capacitação dos professores, pelo menos no que concerne ao nível de formação, vem sendo melhorada. A proporção atual de mestres e doutores em relação ao total de docentes, considerando todas as áreas de conhecimento, atesta tal assertiva. De acordo com dados do Inep (2006), dos 279.058 docentes que atuam em cursos de graduação, 35,40\% são mestres, $20,90 \%$ doutores e 43,70\% têm formação até o nível de especialização. 
É preciso deixar claro neste ponto que não se objetiva aqui fazer juízo de valor sobre o movimento de mudanças em vigor no ensino superior, mas sobretudo considerar a relação de reciprocidade e dependência mútua entre o conteúdo de tais instituições sociais em mudança e a formação dos docentes do curso de administração.

Entretanto, a despeito da crescente qualificação no nível de formação dos docentes de administração, resta saber se tem ocorrido concomitantemente a ela uma evolução nas práticas metodológicas de ensino e avaliação desses profissionais, que possa fazer frente às exigências e dificuldades de aprendizagem que emanam da complexidade da realidade social na atualidade. Esse problema cresce em importância, quando se admite ainda que, apesar do elevado crescimento das escolas de administração e do fato de que a educação em administração se tem tornado um negócio bastante rentável, é reduzida a avaliação do impacto dessas escolas tanto em seus discentes quanto na profissão de administrador (PFEFFER; FONG, 2003). Tal assertiva deixa mais clara ainda a preocupação com a qualidade do ensino nas IES.

Nesse sentido, o atual cenário em que estão circunscritas as organizações de ensino vem demandando, sobretudo em seu corpo docente, profissionais bastante capacitados no que tange às formas de gerar conhecimento, ensinar alunos a desenvolver competências e habilidades gerenciais e, respectivamente, no que diz respeito às formas de avaliar esses processos. Considerando mais apropriadamente o papel das IES dos cursos de administração no desenvolvimento de tais competências e habilidades, faz-se necessário atentar mais especificamente na responsabilidade dos docentes desses cursos, visto o papel fundamental dos professores na interação instituição-aluno e na relação ensinoaprendizagem (FOLLET, I970; MINTZBERG; GOSLING, 2003; MINTZBERG, 2006; VERGARA, 2003).

É com base nesse contexto que o presente estudo tratou de evidenciar as possíveis relações entre o perfil profissional dos docentes de administração das Instituições de Ensino Superior (IES privadas de Curitiba) e as suas tecnologias ${ }^{2}$ de ensino e avaliação. Para tanto, o trabalho está inicialmente estruturado nesta introdução, discussão do Perfil dos Docentes no Ensino Superior, Práticas de Docência e a questão da Qualidade no Ensino Superior em Administração. Na seqüência são apresentados os procedimentos metodológicos que orientaram o estudo, a análise dos dados, a discussão dos resultados e as considerações finais à luz dos achados empíricos. 


\section{PERFIL DOS DOCENTES NO ENSINO SUPERIOR}

A evolução que acompanha as IES brasileiras, de modo mais específico as instituições privadas, tem causado alterações importantes no sistema educacional como um todo. As regras, normas e padrões de organização e tratamento com os docentes das IES têm causado impacto direto no perfil profissional desses educadores.

O perfil apresentado pelos docentes no que tange ao período de trabalho (manhã, tarde, noite), modalidade de contratação (horista, integral, exclusiva), o número maior de instituições que precisam estar ligadas e atividades extradocência influenciam, de forma intensiva, a qualidade do ensino, ensino que, como se sabe historicamente, assenta basicamente na figura do professor, enquanto responsável pelo ato de educar (NASSIF; HANASHIRO, 2002).

Karawejczyk e Estivalete (2002) complementam esse cenário, assegurando que as organizações educacionais atualmente exigem mais ainda dos professores em sua preparação. Em virtude dessas exigências profissionais, torna-se necessário que em IES os docentes apresentem nível de formação adequado, busquem a atualização constante pela participação em eventos científicos e estejam habilitados para desenvolver atividades de pesquisa que resultem na produção de conhecimento científico, observando, contudo, os interesses dos alunos e as especificidades da instituição (TEIXEIRA, 2005). Nassif e Hanashiro (2002) afirmam que as instituições têm aumentado sua preocupação em contratar profissionais competentes em suas áreas de atuação, atentos às questões da sociedade, adeptos do aprendizado contínuo e capacitados para o desenvolvimento e transmissão de conhecimento.

Em paralelo, as mudanças e transformações que têm ocorrido na natureza e no conteúdo do trabalho acadêmico contribuem também para o desenvolvimento de novas competências e na profissionalização dos saberes. O desenvolvimento dessas novas competências tem criado uma atmosfera positiva, na medida em que contribui para a formação e o desenvolvimento de docentes, por meio de mudanças no modo de pensar, ser e agir, inseridos no contexto da atividade de docência (KARAWEJCZYK; ESTIVALETE, 2002).

A capacitação e qualificação de docentes, conforme observam Nassif e Hanashiro (2002), têm aumentado em função da necessidade de o profissional reformular seus conhecimentos e desenvolver novas competências para captar e distribuir o grande volume de informações que surgem constantemente, absorver novas tecnologias, atuar próximo aos alunos e ser parte integrante do processo de mudança e evolução da sociedade. 
Indo além dessas constatações um tanto lógicas, deve-se avaliar os possíveis impactos dessa situação no perfil profissional do docente, nas suas práticas e tecnologias utilizadas na tarefa de educar e, conseqüentemente, na qualidade do ensino e na realidade social. Em consonância com tal assertiva, Paula (200I), tendo em vista a necessidade de adequação às demandas de um mercado de trabalho sedento por produtividade, observa que os professores com freqüência priorizam a sobrevivência profissional em detrimento do poder de transformação da realidade. Nesse sentido, a questão das implicações do perfil profissional dos docentes, na qualidade do ensino, torna-se elemento com dimensões que vão além do tratamento dispensado na maior parte das observações. Daí seria razoável supor a existência de fortes relações entre o perfil do docente, suas práticas de docência e a qualidade do ensino.

\section{PRÁTICAS DE DOCÊNCIA}

Não somente nos cursos de administração o docente do ensino superior pode ser visto como articulador do processo de ensino-aprendizagem. É de sua responsabilidade a tarefa de auxiliar os alunos a refletir constantemente sobre a realidade e desenvolver novos conhecimentos e espírito crítico. Portanto, para atingir este objetivo, o docente deve planejar, coordenar, monitorar e avaliar continuamente o processo referente ao desenvolvimento de sua disciplina, traduzido, principalmente, em suas metodologias de aula e nas formas de avaliação (PROVINCIALI et al., 2005).

As tecnologias de ensino (por exemplo, aulas expositivas, debates e seminários), no corpo das práticas de ensino, estão diretamente ligadas a uma variabilidade desejada na forma de trabalho dos docentes e na qualidade do processo de aprendizagem. Dentro dessa lógica, Valadão Jr., Gabriel e Moriguchi (2005) salientam que o docente tem a função nuclear de desenvolver ambiente propício à compreensão comum, resgatando para isso instrumentos procedentes da ciência, do pensamento e da cultura, com a utilização das mais variadas formas de ensino, com vistas a enriquecer o compartilhamento de experiências, cumprindo-se assim uma das finalidades básicas da educação superior que, conforme a Lei de Diretrizes e Bases da Educação Nacional - LDB (BRASIL, 2006), seria estimular a criação cultural e o desenvolvimento do espírito científico e do pensamento reflexivo.

Porém, o que se pode observar é a incidência de práticas e discursos incongruentes, que conduz ao cerceamento do aprendizado do aluno, fato que, sem dúvida, colabora para a falta de reflexão sobre os conteúdos que lhes são repassados, sendo obrigados a captá-los e reproduzi-los; afinal, a maioria das práticas de ensino parece servir a esse propósito. Conforme afirmam Mintzberg e Gosling 
(2003), o aprendizado se processa quando os conceitos teóricos interagem com as experiências práticas por meio das reflexões, de modo que refletir significa pensar, analisar, sintetizar, sondar e confrontar crenças e valores antigos com novas idéias.

Nessa perspectiva, o uso de práticas acadêmicas tradicionais se reflete no abandono pelo aluno de sua capacidade de transformar o mundo, adaptando-se à posição de produto construído pelo meio em que está inserto, desvinculando sua responsabilidade de indivíduo como agente de mudanças de sua atividade profissional (FREIRE, I983). Motta (I983, p. 55) chama a atenção para o fato de que "[...] as escolas de administração não estão formando administradores-políticos, imbuídos de uma visão transformadora da realidade social, em que pese o conteúdo relativamente crítico de algumas disciplinas".

Entretanto não cabe apenas questionar o conteúdo das disciplinas; é chegada a hora de levantar também questões quanto às práticas de docência nos cursos de administração. Como apropriadamente argumenta Festinalli (2005), o desenvolvimento de reflexões em relação à prática docente possibilita a apropriação e produção de teorias que melhoram as práticas de ensino e ainda permitem auxiliar na superação das deficiências dos docentes acerca do aprender pensando.

\section{QUALIDADE NO ENSINO SUPERIOR EM ADMIINISTRAÇÃO}

O ensino superior é atualmente classificado como uma indústria do setor de serviços. Como organizações que se inserem em tal setor, as IES privadas precisam desenvolver mecanismos e aplicar os recursos necessários no processo de identificação das expectativas e necessidades de seus principais clientes, no caso os estudantes. Todavia esse processo deve dar-se sem esquecer o compromisso da universidade com a sociedade e de seus deveres, de acordo com a legislação vigente (MELLO; DUTRA; OLIVEIRA, 200I).

Em relação aos aspectos de qualidade é pertinente ponderar que as IES se organizaram na década de I990; por intermédio da Associação de Mantenedoras direcionaram esforços no sentido de criar o Instituto Brasileiro de Qualificação de Ensino Superior. Essa entidade de apoio busca, por meio de estudos, pesquisas e encontros, desvendar os conceitos relacionados à qualidade no ensino superior, desenvolvendo procedimentos metodológicos que possibilitem seu diagnóstico e mensuração (CRUBELATTE, 2004).

A despeito dos esforços unificadores desse instituto, permanecem duas principais abordagens no tratamento do conceito de qualidade no ensino superior. A primeira estabelece que a qualidade esteja relacionada à competitividade, uma 
vez que os aspectos do conhecimento são compreendidos como instrumental determinante do processo de inovação e, como a inovação é essencial para uma organização competir no mercado, observa-se relação íntima entre competitividade e ensino. A segunda trabalha com a noção de qualidade relacionada com o compromisso do ensino em contribuir positivamente para a formação política do cidadão (LIMA, 2005).

Na visão de Crubelatte (2004), o problema da qualidade do ensino superior é, antes de tudo, de natureza complexa e ampla demais para ser tratado sob apenas uma perspectiva. Há na questão da qualidade, e principalmente na questão da qualidade do ensino superior, aspectos culturais e políticos, aspectos legais, aspectos educacionais e também organizacionais que não podem ser desconsiderados, sob pena de não se conseguir avaliar adequadamente as conseqüências das políticas formais e ações educacionais implementadas.

Em função da crescente competitividade que aflige o setor educacional, decorrente da multiplicação acelerada de instituições de ensino superior por todo o País, gestores especializados no ramo identificaram como atributos estratégicos da organização a capacidade do aluno em avaliar o serviço prestado, propor possíveis melhorias e, principalmente, atuar como garoto-propaganda, recomendando a instituição para terceiros. Mello, Dutra e Oliveira (200I) afirmam que as instituições de ensino estão tomando consciência da importância de se dar relevância à opinião de seus alunos sobre a qualidade do serviço ofertado, sobretudo no que concerne aos atributos e às práticas de docência do professor e à estrutura das IES.

A confiabilidade e credibilidade de determinada instituição de ensino, bem como a qualidade de um curso superior de graduação, resultam de um conjunto de fatores fortalecidos pelo trabalho em equipe de membros com diferentes atribuições que possibilitam o funcionamento de uma IES, estando eles condicionados pelos objetivos da instituição. Tais fatores são: i) formulação de projetos pedagógicos consistentes; ii) seleção de professores com perfil adequado para executar o projeto pedagógico; e iii) valorização de práticas acadêmicas inovadoras e desafiantes (LIMA, 2005).

A Comissão de Especialistas de Ensino de Administração - CEEAD (2002) também buscou definir os elementos essenciais que devem ser priorizados pelas instituições de ensino superior, tanto em relação ao perfil dos docentes quanto às práticas de docência, visando garantir os padrões de qualidade dos cursos de administração, como estes: i) valores de responsabilidade social, justiça e ética profissional; ii) formação humanística e visão global; iii) formação técnica e científica; iv) capacidade empreendedora; v) atuação interdisciplinar; e vi) contínuo aperfeiçoamento profissional.

Nesse sentido, Valadão Jr., Gabriel e Moriguchi (2005, p. 3) reforçam que a sustentabilidade de um ensino de qualidade pode ser assegurada pelas institui- 
ções por meio de investimentos na formação e adequação do perfil dos docentes, buscando o contínuo aprimoramento das metodologias de aula e dos instrumentos de avaliação utilizados por esses docentes.

Ainda que a busca pela qualidade do ensino tenha conquistado lugar de destaque entre as instituições de ensino superior privadas, uma análise da realidade atual mostra que há longo caminho a ser percorrido pelos dirigentes dessas instituições no sentido de disponibilizar ao mercado um ensino de administração capaz de formar indivíduos conscientes de sua ação na sociedade. Esse distanciamento entre discurso e prática, em relação aos aspectos de qualidade, como apontam os encaminhamentos teóricos, pode estar sendo reforçado pela ineficiência de práticas acadêmicas que dificilmente conseguem proporcionar aos alunos condições favoráveis ao processo de aprendizagem (PAULA, 200I).

Em se tratando de questão tão complexa quanto a qualidade de ensino superior, não parece plausível supor que qualquer legislação, por mais extensa que seja, comporte toda a complexidade do fenômeno (CRUBELLATE, 2004). Dessa forma, Crubellate (2004) considera pouco válida a suposição de que os critérios e as avaliações oficiais, baseados em análise de aspectos e resultados predominantemente quantitativos dos cursos superiores, reflitam mais do que uma ou poucas das facetas implicadas na questão. Caberia, assim, ampliar as dimensões de avaliação ou, pelo menos, identificar quais são essas outras dimensões, bem como entender seus antecedentes. Desse modo, buscou-se inferir que aspectos do perfil do docente podem estar relacionados a práticas de ensino e avaliação mais inovadoras.

\section{PROCEDIMENTOS METODOLÓGICOS}

Com base nos objetivos de pesquisa, o estudo classifica-se como descritivo, sendo qualitativa a fase exploratória e quantitativa a fase descritiva. Essa concepção de pesquisa é recomendada para efetuar a descrição de processos, mecanismos e relacionamentos existentes na realidade do fenômeno estudado, utilizando-se para tanto um conjunto de categorias ou tipos variados de classificações (NEUMAN, 1997).

O método do estudo consiste em um survey (levantamento). Essa forma de levantamento de dados cabe em situações em que se busca descrever determinados traços ou atributos de uma população, necessariamente ainda pouco explorados, do qual, mediante análise quantitativa, se obtêm conclusões de dados coletados (BABBIE, 200I). Dessa forma, o estudo buscou descrever aspectos relacionados ao perfil e práticas de docência do universo de professores de cursos de graduação em administração, das IES privadas, situadas em Curitiba. 
Os procedimentos metodológicos do estudo foram estruturados em algumas etapas mais gerais. O primeiro estágio da pesquisa envolveu a realização de entrevistas semi-estruturadas. Na seqüência foram realizadas as análises das entrevistas para posterior elaboração dos questionários. Antes da aplicação dos questionários realizou-se um teste prévio do instrumento de coleta de dados. Após a coleta dos dados fez-se a tabulação e análise dos dados.

A fase exploratória envolveu cinco entrevistas semi-estruturadas com docentes de cursos de administração em instituições de ensino superior privadas. Buscou-se, por meio destas entrevistas, obter informações necessárias à formatação do questionário para a coleta de dados. Com base nas informações obtidas das entrevistas e do referencial teórico, procedeu-se à construção do questionário, com o objetivo de torná-lo mais adequado à percepção dos professores em relação à realidade da atividade de docência.

O instrumento de coleta de dados foi estruturado em três blocos de questões: i. dados pessoais e formação (gênero, idade, renda, nível de formação acadêmica); ii. dados profissionais (área de atuação, período de trabalho, regime de trabalho, número de faculdades em que leciona, outras atividades, docência como atividade principal ou secundária, participação em grupos de pesquisa, participação em congressos, e número de artigos publicados); e iii. métodos de ensino e avaliação (os métodos de ensino e avaliação são especificados nas tabelas dos resultados). Para medir essas variáveis utilizaram-se escalas nominais; nos métodos de ensino e avaliação, foi dada opção aos entrevistados para acrescentar outras metodologias que não estivessem representadas pelas alternativas da questão.

Para verificação da qualidade do instrumento de coleta de dados, efetuou-se um primeiro teste prévio com oito docentes da área de administração em instituições curitibanas de ensino superior privado. Os entrevistados foram selecionados com base nos critérios estabelecidos por Marconi e Lakatos (I990) e Vergara (I998): i. aspectos de acessibilidade (seleção de elementos pela facilidade de acesso a eles); e ii. tipicidade (seleção de elementos representativos na população). Esses questionários foram aplicados individualmente, com o acompanhamento dos pesquisadores; os respondentes foram instruídos a marcar as questões em que encontraram dúvidas e descrever os motivos das dúvidas e sugestões para posterior reformulação das questões.

Após a aplicação do teste prévio, os pesquisadores realizaram a reformulação de alguns itens do questionário com base nas observações efetuadas pelos docentes. Na reformulação alguns aspectos foram incluídos e outros modificados.

Para a definição da amostra, realizou-se um levantamento com Conselho Regional de Administração (CRA), em Curitiba, Paraná, buscando identificar quais instituições de ensino superior particulares existentes na capital oferecem curso de administração. Por meio da coleta dessas informações, identificou-se 
que o universo da pesquisa é formado por 24 instituições. Depois de discussões, os pesquisadores decidiram realizar o estudo, envolvendo o universo total de instituições localizadas na capital paranaense.

Após esses procedimentos, foram efetuadas as devidas alterações nos questionários e, posteriormente, distribuíram-se 934 questionários para os professores dos cursos de administração de 24 IES privadas de Curitiba, com o objetivo de levantar informações necessárias à caracterização desses docentes e suas práticas de ensino e avaliação. Recolheram-se 2I4 questionários válidos que, posteriormente, foram tabulados e tratados estatisticamente com o auxílio do software estatístico SPSS I3 for Windows. O tratamento dos dados envolveu a análise de estatísticas descritivas e o teste de comparação de proporções Qui Quadrado $\left(\chi^{2}\right)$.

\section{ANÁLISE DOS DADOS}

Com o intuito de descrever o perfil dos docentes pesquisados, utilizaram-se estatísticas descritivas no exame das características dos especialistas, mestres e doutores. Também foram analisadas as práticas de ensino e avaliação dos docentes, visando ao objetivo geral do estudo.

Com relação à amostra, dos 2I4 respondentes foram observados 208 questionários sem missing values na questão sexo do entrevistado ou nível de formação. Desses 208 docentes 70,70\% são do sexo masculino e 29,30\% do sexo feminino. Do grupo dos homens, 29,30\% são especialistas, 52,40\% mestres e I $8,30 \%$ doutores. Do grupo das mulheres, I8,05\% são especialistas, 63,90\% mestres e I $8,05 \%$ doutores. A média de idade dos pesquisados é de 42 anos com um desvio padrão de 9,5 anos. Não foi encontrada diferença na média de idade para os pesquisados segundo seus níveis de formação. Visando à parcimônia quanto ao número de categorias de análise, os mestrandos foram incluídos na categoria mestres e os doutorandos na categoria doutores.

Uma segunda preocupação quanto ao perfil dos docentes de administração foi relatar as áreas de atuação desses profissionais (disciplinas lecionadas de acordo com o nível de formação). Para tanto, realizou-se o teste Qui Quadrado $\left(\chi^{2}\right)$ para a verificação das diferenças entre as proporções de docentes especialistas, mestres e doutores nas principais disciplinas da graduação em administração. O teste Qui Quadrado, $\left(\chi^{2}\right)$ - Pearson Chi-Square: $\chi^{2}=\Sigma\left[(\mathrm{o}-\mathrm{e})^{2} / \mathrm{e}\right]$, é um teste de diferença de proporções em que $o$ é a freqüência observada para a classe, e $e$ é a freqüência esperada daquela classe (SPIEGEL, I988; TRIOLA, I999). Um resumo dos resultados desse teste para as áreas de atuação consta na Tabela 2. 


\section{TABELA 2}

ÁREA DE ATUAÇÃO EM VALORES ABSOLUTOS E PERCENTUAIS DE ACORDO COM A FORMAÇÃO

\begin{tabular}{|c|c|c|c|c|c|}
\hline & ESPECIALIZAÇÃO & MESTRADO & DOUTORADO & $\chi^{2}$ & P-VALUE \\
\hline Leciona recursos humanos & $08(03,80 \%)$ & $13(06,20 \%)$ & $04(01,90 \%)$ & & \\
\hline Não leciona & $48(22,70 \%)$ & $104(49,30 \%)$ & $34(16,10 \%)$ & 0,443 & 0,801 \\
\hline Leciona marketing & $06(02,80 \%)$ & $20(09,50 \%)$ & $05(02,40 \%)$ & & \\
\hline Não leciona & $50(23,70 \%)$ & $97(46,00 \%)$ & $33(15,60 \%)$ & 1,317 & 0,518 \\
\hline Leciona finanças & $12(05,70 \%)$ & $22(10,40 \%)$ & $04(01,90 \%)$ & & \\
\hline Não leciona & $44(20,90 \%)$ & $95(45,00 \%)$ & $34(16,10 \%)$ & 1,934 & 0,380 \\
\hline $\begin{array}{l}\text { Leciona produção e } \\
\text { tecnologia }\end{array}$ & $07(03,30 \%)$ & $16(07,60 \%)$ & $11(05,20 \%)$ & & \\
\hline Não leciona & $49(23,20 \%)$ & $101(47,90 \%)$ & $27(12,80 \%)$ & 5,686 & 0,058 \\
\hline Leciona empreendedorismo & $06(02,80 \%)$ & $09(04,30 \%)$ & $04(01,90 \%)$ & & \\
\hline Não leciona & $50(23,70 \%)$ & $108(51,20 \%)$ & $34(16,10 \%)$ & 0,553 & 0,758 \\
\hline Leciona estratégia & $03(01,40 \%)$ & $10(04,70 \%)$ & $03(01,40 \%)$ & & \\
\hline Não leciona & $53(25,10 \%)$ & $107(50,70 \%)$ & $35(16,60 \%)$ & 0,556 & 0,757 \\
\hline $\begin{array}{l}\text { Leciona teoria das } \\
\text { organizações }\end{array}$ & $02(00,90 \%)$ & $18(08,50 \%)$ & $04(01,90 \%)$ & & \\
\hline Não leciona & $54(25,60 \%)$ & $99(46,90 \%)$ & $34(16,10 \%)$ & 5,276 & 0,072 \\
\hline $\begin{array}{l}\text { Leciona comércio } \\
\text { internacional }\end{array}$ & $02(00,90 \%)$ & $04(01,90 \%)$ & $03(01,40 \%)$ & & \\
\hline Não leciona & $54(25,60 \%)$ & $113(53,60 \%)$ & $35(16,60 \%)$ & 1,497 & 0,473 \\
\hline $\begin{array}{l}\text { Leciona sistemas de } \\
\text { informações }\end{array}$ & $06(02,80 \%)$ & $11(05,20 \%)$ & $05(02,40 \%)$ & & \\
\hline Não leciona & $50(23,70 \%)$ & $106(50,20 \%)$ & $33(15,60 \%)$ & 0,440 & 0,802 \\
\hline
\end{tabular}

Fonte: Dados primários. 
Como sugerem os resultados do teste Qui Quadrado $\left(\chi^{2}\right)$, não existe diferença ou qualquer relação mais próxima entre as disciplinas que esses docentes lecionam e seu nível de formação. Entretanto, a observação da proporção de docentes que lecionam Produção e Tecnologia apresenta diferença, quando se considera um $p$-value $=0,10, \chi^{2}=5,686$ com significância de 0,058 . Não que se considere para o estudo um alfa de o,Io, mas tal constatação indica que em amostras maiores essa diferença talvez possa ser percebida. Em adição, é possível ressaltar mais alta proporção de doutores lecionando essa disciplina, em comparação aos mestres e especialistas. Da mesma forma, a proporção de docentes mestres que lecionam Teoria das Organizações e disciplinas correlatas, como TGA, parece diferenciar-se dos especialistas e doutores, quando se considera um alfa $<0$, IO como nível de significância.

Após a descoberta de poucas diferenças no que tange à idade e disciplinas de atuação dos docentes, de acordo com seu nível de formação, buscou-se entender qual o perfil do pesquisado em relação às características que se reportam ao período do dia em que leciona, regime de trabalho, número de faculdades em que leciona, exercício de outras atividades paralelas à docência, atividade de docência como atividade principal ou secundária, participação ou não de grupos de pesquisa, número de participações em congressos, número de artigos publicados, gênero e renda.

Nessas análises encontraram-se diferenças estatisticamente significativas $(p$-value $<0,05)$ para as categorias docência, como atividade principal ou secundária, participação ou não em grupos de pesquisa, número de participações em congressos, número de artigos publicados e renda.

Quanto às categorias "leciona no período da manhã ou não, leciona no período da noite ou não, e possui outras atividades extradocência”, as diferenças estatísticas aparecem somente com nível de significância < o,Io, conforme Tabela 3. 


\section{TABELA 3}

PERFIL DOS DOCENTES PESQUISADOS EM

VALORES ABSOLUTOS E PERCENTUAIS

\begin{tabular}{|c|c|c|c|c|c|}
\hline & ESPECIALIZAÇÃO & MESTRADO & DOUTORADO & $\chi^{2}$ & P-VALUE \\
\hline $\begin{array}{l}\text { Não leciona no período da } \\
\text { manhã }\end{array}$ & $37(17,62 \%)$ & $60(28,57 \%)$ & $16(07,62 \%)$ & & \\
\hline $\begin{array}{l}\text { Leciona no período da } \\
\text { manhã }\end{array}$ & $19(09,05 \%)$ & $56(26,67 \%)$ & $22(10,48 \%)$ & 5,685 & 0,058 \\
\hline $\begin{array}{l}\text { Não leciona no período da } \\
\text { tarde }\end{array}$ & $46(21,90 \%)$ & $91(43,33 \%)$ & $26(12,38 \%)$ & & \\
\hline Leciona no período da tarde & $10(04,76 \%)$ & $25(11,90 \%)$ & $12(05,71 \%)$ & 2,556 & 0,279 \\
\hline $\begin{array}{l}\text { Não leciona no período da } \\
\text { noite }\end{array}$ & $01(00,48 \%)$ & $00(00,00 \%)$ & $02(00,95 \%)$ & & \\
\hline Leciona no período da noite & $55(26,19 \%)$ & $116(55,24 \%)$ & $36(17,14 \%)$ & 5,700 & 0,058 \\
\hline Não horista & $05(02,39 \%)$ & $11(05,26 \%)$ & $07(03,35 \%)$ & & \\
\hline Horista & $50(23,92 \%)$ & $105(50,24 \%)$ & $31(14,83 \%)$ & 2,614 & 0,271 \\
\hline Sem dedicação integral & $52(24,88 \%)$ & $109(52,15 \%)$ & $33(15,79 \%)$ & & \\
\hline Dedicação integral & $03(01,44 \%)$ & $07(03,35 \%)$ & $05(02,39 \%)$ & 2,513 & 0,285 \\
\hline Sem dedicação exclusiva & $54(25,84 \%)$ & $109(52,15 \%)$ & $36(17,22 \%)$ & & \\
\hline Dedicação exclusiva & $01(00,48 \%)$ & $07(03,35 \%)$ & $02(00,96 \%)$ & 1,479 & 0,477 \\
\hline \multicolumn{6}{|l|}{ Número de Faculdades } \\
\hline Uma faculdade & $35(16,59 \%)$ & $65(30,81 \%)$ & $17(08,06 \%)$ & & \\
\hline Duas faculdades & $17(08,06 \%)$ & $37(17,54 \%)$ & $15(07,11 \%)$ & & \\
\hline Três faculdades & $04(01,90 \%)$ & $12(05,69 \%)$ & $03(01,42 \%)$ & & \\
\hline Quatro ou mais & $00(00,00 \%)$ & $03(01,42 \%)$ & $03(01,42 \%)$ & 7,463 & 0,280 \\
\hline Possui outras atividades & $45(22,17 \%)$ & $85(41,87 \%)$ & $32(15,76 \%)$ & & \\
\hline Não possui outras atividades & $06(02,96 \%)$ & $29(14,29 \%)$ & $06(02,96 \%)$ & 4,651 & 0,098 \\
\hline Docência atividade principal & $22(10,43 \%)$ & $69(32,70 \%)$ & $23(10,90 \%)$ & & \\
\hline $\begin{array}{l}\text { Docência atividade } \\
\text { secundária }\end{array}$ & $34(16,11 \%)$ & $48(22,75 \%)$ & $15(07,11 \%)$ & 6,699 & 0,035 \\
\hline
\end{tabular}




\section{TABELA 3 (CONTINUAÇÃo)}

\section{PERFIL DOS DOCENTES PESQUISADOS EM}

VALORES ABSOLUTOS E PERCENTUAIS

\begin{tabular}{|c|c|c|c|c|c|}
\hline & ESPECIALIZAÇÃO & MESTRADO & DOUTORADO & $\chi^{2}$ & P-VALUE \\
\hline $\begin{array}{l}\text { Participa de grupos de } \\
\text { pesquisa }\end{array}$ & $01(00,48 \%)$ & $21(10,10 \%)$ & $13(06,25 \%)$ & & \\
\hline $\begin{array}{l}\text { Não participa de grupos de } \\
\text { pesquisa }\end{array}$ & $54(25,96 \%)$ & $94(45,19 \%)$ & $25(12,02 \%)$ & 18,019 & 0,001 \\
\hline \multicolumn{6}{|l|}{ Participações em congressos } \\
\hline Nenhum & $10(04,76 \%)$ & $15(07,14 \%)$ & $02(00,95 \%)$ & & \\
\hline Um & $11(05,24 \%)$ & $09(04,29 \%)$ & $08(03,81 \%)$ & & \\
\hline Dois & $10(04,76 \%)$ & $29(13,81 \%)$ & $04(01,90 \%)$ & & \\
\hline Três & $13(06,19 \%)$ & $16(07,62 \%)$ & $10(04,76 \%)$ & & \\
\hline Quatro & $03(01,43 \%)$ & $16(07,62 \%)$ & $00(00,00 \%)$ & & \\
\hline Cinco ou mais & $09(04,29 \%)$ & $31(14,76 \%)$ & $14(06,67 \%)$ & 26,425 & 0,003 \\
\hline \multicolumn{6}{|l|}{ Artigos publicados } \\
\hline Nenhum & $43(20,77 \%)$ & $46(22,22 \%)$ & $07(03,38 \%)$ & & \\
\hline Um & $07(03,38 \%)$ & $20(09,66 \%)$ & $09(04,35 \%)$ & & \\
\hline Dois & $02(00,97 \%)$ & $12(05,80 \%)$ & $07(03,38 \%)$ & & \\
\hline Três & $03(01,45 \%)$ & $12(05,80 \%)$ & $04(01,93 \%)$ & & \\
\hline Quatro & $00(00,00 \%)$ & $09(04,35 \%)$ & $02(00,97 \%)$ & & \\
\hline Cinco ou mais & $00(00,00 \%)$ & $16(07,73 \%)$ & $08(03,86 \%)$ & 43,627 & 0,000 \\
\hline Masculino & $43(20,67 \%)$ & $77(37,02 \%)$ & $27(12,98 \%)$ & & \\
\hline Feminino & $11(05,29 \%)$ & $39(18,75 \%)$ & $11(05,29 \%)$ & 3,125 & 0,210 \\
\hline \multicolumn{6}{|l|}{ Renda } \\
\hline Até $\mathrm{R} \$ 2.000,00$ & $23(11,00 \%)$ & $31(14,83 \%)$ & $04(01,91 \%)$ & & \\
\hline $\begin{array}{l}\text { De } R \$ 2.001,00 \text { a } \\
4.000,00\end{array}$ & $17(08,13 \%)$ & $44(21,05 \%)$ & $04(01,91 \%)$ & & \\
\hline $\begin{array}{l}\text { De } R \$ 4.001,00 \text { a } \\
5.000,00\end{array}$ & $05(02,39 \%)$ & $08(03,83 \%)$ & $10(04,78 \%)$ & & \\
\hline Acima de $R \$ 5.000,00$ & $10(04,78 \%)$ & $34(16,27 \%)$ & $19(09,09 \%)$ & 32,590 & 0,000 \\
\hline
\end{tabular}


A docência como atividade principal apresentou um valor para $\chi^{2}=6,699$ com um $p$-value $=0,035$; portanto com diferenças estatisticamente significativas. Esse resultado sugeriu percentual mais reduzido no número de especialistas que têm a atividade de docência como atividade principal.

A participação ou não em grupos de pesquisa tem um valor de $\chi^{2}=18$, oI9 com $p$-value $=0,00$ I. A diferença parece residir no número de doutores que participam de grupos de pesquisa. Vale notar que os mestres (categoria que inclui os mestrandos) têm percentual inferior, mas que não se compara aos especialistas. Desses últimos apenas I especialista, dentro de 55 docentes, com essa formação, participa de algum grupo de pesquisa.

Quanto ao número de participações em congressos, observa-se quase o mesmo cenário. Essa variável da pesquisa tem valor de $\chi^{2}=26,425 \mathrm{com} p$-value $=$ 0,003 . O número de participações em congressos é mais reduzido na amostra de especialistas. Esse resultado parece estar proximamente relacionado ao resultado anterior, que se refere ao número de participações em congressos.

O número de artigos publicados tem valor de $\chi^{2}=43,627 \mathrm{com} p$-value $=$ $\circ, 0 \circ 0$. O maior percentual de especialistas não tem nenhum artigo publicado. Os mestres e doutores também apresentam percentual alto nessa mesma categoria; todavia estão mais uniformemente distribuídos nas outras categorias em comparação aos especialistas.

No que concerne à renda, essa variável apresentou valor de $\chi^{2}=32,590 \mathrm{com}$ $p$-value $=0,000$. Parece existir correlação positiva entre nível de formação e faixa de renda.

Depois de analisados os dados referentes ao perfil dos especialistas à luz de seu nível de formação, buscou-se identificar o grau de utilização das formas mais comuns de metodologias de aula e avaliação segundo a literatura e as entrevistas conduzidas na fase exploratória do estudo. Os valores absolutos e percentuais constam na Tabela 4. 
TABELA 4

METODOLOGIAS DE AULA EM VALORES

ABSOLUTOS E PERCENTUAIS

\begin{tabular}{lccccc}
\hline & ESPECIALIZAÇÃO & MESTRADO & DOUTORADO & $\chi^{2}$ & P-VALUE \\
\hline Não utiliza aula expositiva & $02(00,90 \%)$ & $10(04,50 \%)$ & $01(00,45 \%)$ & & \\
\hline Utiliza aula expositiva & $54(24,32 \%)$ & $117(52,70 \%)$ & $38(17,12 \%)$ & 2,620 & 0,270 \\
\hline Não utiliza debates & $27(12,80 \%)$ & $63(29,86 \%)$ & $14(06,64 \%)$ & & \\
\hline Utiliza debates & $29(13,74 \%)$ & $54(25,59 \%)$ & $24(11,37 \%)$ & 3,353 & 0,187 \\
\hline Não utiliza seminário & $39(18,48 \%)$ & $79(37,44 \%)$ & $20(09,48 \%)$ & & \\
\hline Utiliza seminário & $17(08,06 \%)$ & $38(18,01 \%)$ & $18(08,53 \%)$ & 3,416 & 0,181 \\
\hline
\end{tabular}

Fonte: Dados primários.

Como sugerem os resultados do teste Qui Quadrado $\left(\chi^{2}\right)$, na Tabela 4, não existem diferenças nas metodologias de aula entre os diferentes níveis de formação. Mas, de acordo com esses achados, a aula expositiva, em comparação com as outras alternativas, predomina enquanto metodologia de ensino. A utilização de debates e seminários aparece com freqüência bem menor em relação à aula expositiva.

Identificadas as freqüências quanto às principais metodologias de ensino, também foram apreciadas as diferenças nas formas de avaliação, segundo o nível de formação. Nesse último bloco de questões, os entrevistados eram solicitados a responder quais as formas de avaliação utilizadas por eles. As opções nessa questão envolveram a participação do aluno em aula, a utilização de seminários ministrados pelos alunos, prova bimestral, a utilização de resenhas sobre artigos ou livros, a utilização de qualquer tipo de trabalho final da disciplina, a avaliação da presença nas aulas, trabalhos em equipe, aulas com inclinação mais prática e a utilização de dinâmicas de grupo.

No teste Qui Quadrado $\left(\chi^{2}\right)$ para verificação de diferença de proporções, foi identificada somente a utilização de seminários com diferenças significativas em nível de significância inferior a 0,05. A utilização dessa forma de avaliação apresentou valor para o $\chi^{2}=8,574$ e $p$-value $=0$,oI4. Os resultados do Qui Quadrado $\left(\chi^{2}\right)$ para todas as formas de avaliação constam na Tabela 5 . 


\section{TABELA 5}

FORMAS DE AVALIAÇÃO EM VALORES

ABSOLUTOS E PERCENTUAIS

\begin{tabular}{|c|c|c|c|c|c|}
\hline & ESPECIALIZAÇÃO & MESTRADO & DOUTORADO & $\chi^{2}$ & P-VALUE \\
\hline $\begin{array}{l}\text { Não utiliza participação } \\
\text { em aula }\end{array}$ & $24(11,37 \%)$ & $61(28,91 \%)$ & $21(09,95 \%)$ & & \\
\hline $\begin{array}{l}\text { Utiliza participação em } \\
\text { aula }\end{array}$ & $32(15,17 \%)$ & $56(26,54 \%)$ & $17(08,06 \%)$ & 1,773 & 0,412 \\
\hline Não utiliza seminário & $41(19,43 \%)$ & $78(36,97 \%)$ & $17(08,06 \%)$ & & \\
\hline Utiliza seminário & $15(07,11 \%)$ & $39(18,48 \%)$ & $21(09,95 \%)$ & 8,574 & 0,014 \\
\hline Não utiliza prova & $09(04,27 \%)$ & $17(08,06 \%)$ & $04(01,90 \%)$ & & \\
\hline Utiliza prova & $47(22,27 \%)$ & $100(47,39 \%)$ & $34(16,11 \%)$ & 0,592 & 0,744 \\
\hline Não utiliza resenha & $47(22,27 \%)$ & $96(45,50 \%)$ & $34(16,11 \%)$ & & \\
\hline Utiliza resenha & $09(04,27 \%)$ & $21(09,95 \%)$ & $04(01,90 \%)$ & 1,169 & 0,557 \\
\hline Não utiliza trabalho final & $46(21,80 \%)$ & $96(45,50 \%)$ & $26(12,32 \%)$ & & \\
\hline Utiliza trabalho final & $10(04,74 \%)$ & $21(09,95 \%)$ & $12(05,69 \%)$ & 3,583 & 0,167 \\
\hline $\begin{array}{l}\text { Não utiliza presença em } \\
\text { aula }\end{array}$ & $44(20,85 \%)$ & $94(44,55 \%)$ & $32(15,17 \%)$ & & \\
\hline Utiliza presença em aula & $12(05,69 \%)$ & $23(10,90 \%)$ & $06(02,84 \%)$ & 0,468 & 0,791 \\
\hline $\begin{array}{l}\text { Não utiliza trabalho em } \\
\text { equipe }\end{array}$ & $16(07,58 \%)$ & $38(18,01 \%)$ & $11(05,21 \%)$ & & \\
\hline $\begin{array}{l}\text { Utiliza trabalho em } \\
\text { equipe }\end{array}$ & $40(18,96 \%)$ & $79(37,44 \%)$ & $27(12,80 \%)$ & 0,346 & 0,841 \\
\hline Não utiliza aulas práticas & $37(17,54 \%)$ & $82(38,86 \%)$ & $26(12,32 \%)$ & & \\
\hline Utiliza aulas práticas & $19(09,00 \%)$ & $35(16,59 \%)$ & $12(05,69 \%)$ & 0,286 & 0,867 \\
\hline Não utiliza dinâmica & $41(19,43 \%)$ & $83(39,34 \%)$ & $33(15,64 \%)$ & & \\
\hline Utiliza dinâmica & $15(07,11 \%)$ & $34(16,11 \%)$ & $05(02,37 \%)$ & 3,866 & 0,145 \\
\hline
\end{tabular}

Fonte: Dados primários. 


\section{DISCUSSÃO DOS RESULTADOS}

Por meio das análises dos dados, delinearam-se os perfis dos docentes investigados e as suas práticas de docência. Esse exercício de perfilação dos respondentes foi levantado com base mais específica nos dados pessoais e formação, dados profissionais e as suas metodologias de ensino e avaliação.

Quanto aos dados pessoais, foi possível verificar que na graduação do curso de administração existe uma média de 42 anos de idade dos docentes. Todavia, o desvio padrão dessa média é de 9,5 anos, o que retrata uma amostra bastante heterogênea de professores quanto à faixa etária. Fato que possivelmente é benéfico para o ensino, pesquisa e extensão, em razão da combinação entre a experiência e a energia de docentes em início de carreira.

Também foi observado que não existe diferença na proporção de homens e mulheres nas categorias especialistas, mestres e doutores. Uma boa constatação, quando se pensa nas diferenças de oportunidades e maiores exigências no trabalho para o sexo feminino. Contudo, quando se atenta ao percentual geral de homens e mulheres na docência, é relativamente clara a proporção diferenciada de gênero nesse curso. Dos 208 docentes da amostra 70,70\% são do sexo masculino. Não cabe aqui discutir os antecedentes dessa proporção, mas vale atentar para a necessidade de estudos futuros que venham a explorar de forma mais pormenorizada essa realidade.

Quando se compara a renda com os níveis de formação, parece haver maior percentual de doutores, mestres e especialistas nas faixas mais altas, faixas médias e faixas mais baixas de renda, respectivamente: é possível afirmar que compensa fazer a pós-graduação stricto sensu.

Quando se analisa o que foi rotulado aqui como dados profissionais, aparecem dados interessantes quanto às disciplinas de atuação. Ainda que não tenha sido identificada diferença em qualquer disciplina com um $p$-value $<0,05 \mathrm{e}$ somente para um $p$-value < 0 ,IO, importa considerar os resultados para as disciplinas de Teoria das Organizações e áreas relacionadas, e Produção e Tecnologia. Em outros estudos, com amostras maiores, essas diferenças talvez possam ser mais claramente percebidas.

A proporção de professores que lecionam Teoria das Organizações ou TGA é bem inferior na categoria de especialistas, o que pode ser justificado em razão de os cursos de especialização não apresentarem com freqüência essas disciplinas.

A comparação da proporção de professores que lecionam Produção e Tecnologia sugere provável diferença no número de mestres e doutores em relação aos especialistas. Prováveis explicações para essas diferenças podem residir tanto na argumentação anterior, referente à disciplina de Teoria das Organizações, quanto ao número de mestres e mestrandos e doutores e doutorandos da cidade 
pesquisada que se vêm formando no curso de Engenharia da Produção da UFSC. Esse curso tem oferecido número elevado de vagas em comparação a outros programas de mestrado e doutorado.

Também foi possível notar que os especialistas concebem a atividade de docência como ocupação secundária, em comparação aos mestres e doutores. É muito comum que esses profissionais atuem o dia todo em empresas fora do setor de educação e complementem sua renda com algumas aulas no período noturno.

Outras características que são mais atreladas ao especialista residem na sua dedicação ao campo científico. O profissional com esse nível de formação, pelo menos na amostra pesquisada, é aquele que menos participa de grupos de pesquisa, que tem os números mais reduzidos de participações em congressos e artigos publicados.

Verificadas as principais características desses profissionais à luz de seu nível de formação buscou-se entender se existiam algumas diferenças quanto a sua forma de trabalho, mais especificamente em suas práticas de ensino e avaliação. O que foi possível constatar é que não existem diferenças na forma de ensino entre especialistas, mestres e doutores. E, nas formas de avaliação, somente a utilização de seminários é mais freqüente nas categorias de mestre e doutor. Tal fato pode estar atrelado à própria formação dos mestres e doutores, pois o desenvolvimento de seminários é a prática de avaliação mais comum em vários programas de mestrado e doutorado. Se isso realmente estiver relacionado, caberia então aos programas de mestrado e doutorado a institucionalização de tais tecnologias nas práticas de docência dos seus futuros egressos.

\section{CONSIDERAÇÕES FINAIS}

Em resumo, o artigo delineia o perfil dos docentes especialistas, mestres e doutores e identifica alto grau de homogeneidade das práticas de ensino e avaliação entre os distintos níveis de qualificação. Nesse sentido, talvez seja razoável considerar a responsabilidade dos cursos de pós-graduação, em nível de mestrado e doutorado, quanto ao desenvolvimento e treinamento dos futuros docentes de administração em novas tecnologias de ensino e avaliação que têm, seguramente, impacto de grande intensidade em algumas das facetas da qualidade no ensino superior.

Deve-se chamar atenção quanto à preocupação em torno dos achados da pesquisa. Os mestres e doutores têm a atividade de docência como ocupação principal, são mais qualificados, mais dedicados à produção científica, mas ensinam os graduandos de administração basicamente da mesma forma que os especialistas. 
Como argumenta Cunha (I997), não podemos esquecer que é a aula universitária o locus concreto do ensino, em que professor, aluno e conhecimento interagem em construção coletiva e em exercício que depende cada vez mais de técnicas de ensino mais eficientes e inovadoras. Mas, a despeito dessa lógica, a prática pedagógica atual reforça a relação vertical que envolve professor e aluno, sendo o professor mero condutor de informações. Nesse ponto cabe esclarecer que esse ritual é a expressão das concepções de aprendizagem, de conhecimento e, sobretudo, da sociedade em que se inserem as relações de ensino-aprendizagem. A mesma autora acrescenta:

A maioria dos professores não faz uma reflexão rigorosa sobre suas práticas e, como produto dos processos acabados que o formaram, repete os mesmos rituais pedagógicos que viveu [...] os atuais professores se inspiram nas práticas vividas quando decidem como ensinar (CUNHA, I997, p. 8I).

Como é possível inferir das argumentações de Cunha (I997), os professores reproduzem uma lógica que muitos deles negam. Os docentes e as universidades sustentam um discurso de ensino voltado para a prática, com metodologias inovadoras, com atuação interdisciplinar, mas, na verdade, reproduzem aquilo que condenam: ensino de qualidade freqüentemente medíocre e desconectado dos desafios atuais da realidade que a sociedade enfrenta.

De forma geral, uma reflexão acerca dos achados empíricos conduz a uma série de preocupações quanto à qualidade do ensino superior. Por onde andam as novas tecnologias do ensino superior? Qual a qualidade da preparação pedagógica que os cursos de mestrado e doutorado oferecem? Quais as possibilidades de mudança nesse cenário, quando se vê os alunos desses cursos ingressarem nos programas de mestrado e doutorado que contemplam um ensino assentado basicamente na mesma lógica?

\section{REFERÊNCIAS}

BABBIE, E. Métodos de pesquisas de survey. Belo Horizonte: Ed. UFMG, 200 I.

BRASIL, MINISTÉRIO DA EDUCAÇÃO E CULTURA. Lei de Diretrizes e Bases da Educação Nacional. Lei no 9.394 de dezembro de i996. Disponível em: <http://www.mec.gov.br>. Acesso em: $20 / 3 / 2006$.

COMISSÃO DE ESPECIALISTAS DE ENSINO DE ADMINISTRAÇÃO DO MINISTÉRIO DA EDUCAÇÃO E DO DESPORTO - CEEAD. Padrões de qualidade para cursos de graduação em administração. Brasília: MEC, 2002. 
CRUBELATTE, J. M. Parâmetros de qualidade de ensino superior: análise institucional em IES privadas do estado de São Paulo. 2004. 358 p. Tese (Doutorado em Administração)-Fundação Getulio Vargas/ EAESP/FGV, São Paulo, 2004.

CUNHA, M. I. Aula universitária: inovação e pesquisa. In: MOROSINI, M.; LEITE, D. B. C. (Orgs.). Universidade futurante. São Paulo: Papirus Editora, I997.

FESTINALLI, R. C. A formação de mestres em administração: por onde andamos? In: ENCONTRO DA ASSOCIAÇÃO NACIONAL DE PROGRAMAS DE PÓS-GRADUAÇÃO EM ADMINISTRAÇÃO, 29., 2005, Brasília. Anais... Brasília: ANPAD, 2005.

FOLLET, M. P. The teacher-student relation. Administrative Science Quarterly, Ithaca, v. I5, n. 2, p. I37-I49, I970.

FREIRE, P. Pedagogia do oprimido. I2. ed. Rio de Janeiro: Paz e Terra, I983.

INSTITUTO NACIONAL DE ESTUDOS E PESQUISAS EDUCACIONAIS ANÍSIO TEIXEIRA - INEP. Censo da educação superior: resultados e tendências. Disponível em: <http://www.inep.gov. br/superior/censosuperior/resultados/resultados_tendencias.htm>. Acesso em: 20 mar. 2006.

KARAWEJCZYK, T. C.; ESTIVALETE, V. F. B. O sentido do trabalho e o desenvolvimento de competências: perspectivas sob a ótica do professor universitário. In: ENCONTRO DE ESTUDOS ORGANIZACIONAIS, 2., 2002, Recife. Anais... Recife: ANPAD, 2002.

LIMA, M. C. Ensino, pesquisa, capacitação e titulação docente no ensino da graduação em administração. In: ENCONTRO NACIONAL DOS CURSOS DE GRADUAÇÃO EM ADMINISTRAÇÃO, I6., 2005, Belo Horizonte. Anais... Belo Horizonte: ANGRAD, 2005.

MARCONI, M. A.; LAKATOS, E. M. Técnicas de pesquisa: planejamento e execução de pesquisas, amostragens e técnicas de pesquisa, elaboração e interpretação de dados. São Paulo: Atlas, I990. MELLO, S. C. B.; DUTRA, H. F. O.; OLIVEIRA, P. A. S. Avaliando a qualidade de serviço educacional numa IES: o impacto da qualidade percebida na apreciação do aluno de graduação. Organização $\&$ Sociedade, Salvador, v. 8, n. 2I, p. I25-I37, maio/ago. 200I.

MINTZBERG, H. MBA? Não, obrigado! Porto Alegre: Bookman, 2006.

MINTZBERG, H.; GOSLING, J. Educando administradores além das fronteiras. Revista de Administração de Empresas, São Paulo, v. 43, n. 2, p. 29-43, abr./maio/jun. 2003.

MOTTA, F. C. P. A questão da formação do Administrador. Revista de Administração de Empresas, São Paulo, v. 23, n. 4, p. 53-55, out./dez. I983.

NASSIF, V. M. J.; HANASHIRO, D. M. M. A competitividade das universidades particulares à luz de uma visão baseada em recursos. Revista de Administração Mackenzie, São Paulo, v. 3, n. I, p. 95-II4, jan./jun. 2002.

NEUMAN, L. W. Social research methods: qualitative and quantitative approaches. Boston: Allyn \& Bacon, I997.

NICOLINI, A. Qual será o futuro das fábricas de administradores? Revista de Administração de Empresas, São Paulo, v. 43, n. 2, p. 44-54, abr./maio/jun. 2003.

PAULA, A. P. P. Tragtenberg e a resistência da crítica: pesquisa e ensino na administração hoje. Revista de Administração de Empresas, São Paulo, v. 4I, n. 3, p. 77-8I, jul./set. 200 I.

PFEFFER, J.; FONG, C. T. O fim das escolas de negócio? Revista de Administração de Empresas, São Paulo, v. 43, n. 2, p. II-28, abr./maio/jun. 2003.

PROVINCIALI, V. L. N. et al. A graduação em administração sob a ótica discente: um estudo comparativo em instituições de ensino superior de Sergipe. Caderno de Pesquisas em Administração, São Paulo, v. I2, n. 2, p. 19-36, abr./jun. 2005. 
SPIEGEL, M. R. Estatística. 2. ed. São Paulo: McGraw-Hill do Brasil, ı988.

TEIXEIRA, C. H. A identificação de competências em instituições de ensino superior: uma abordagem estratégica. In: SEMINÁRIOS EM ADMINISTRAÇÃO, 8., 2005, São Paulo, Anais... São Paulo: SEMEAD, 2005 .

TRIOLA, M. F. Introdução à estatística. 7. ed. Rio de Janeiro: LTC, I999.

VALADÃO JR., V. M.; GABRIEL, F. S.; MORIGUCHI, S. N. Avaliação do curso de administração da UFU: validando os 8 A's. In: SEMINÁRIOS EM ADMINISTRAÇÃO, 8., 2005, São Paulo. Anais... São Paulo: SEMEAD, 2005.

VERGARA, S. C. Projetos e relatórios de pesquisa em administração. São Paulo: Atlas, I998.

Repensando a relação ensino-aprendizagem em administração: argumentos teóricos, práticas e recursos. Organização \& Sociedade, Salvador, v. IO, n. 28, p. I3I-I42, set./dez. 2003.

\section{TRAMITAÇ ÃO}

Recebido em 11/12/2006

Aprovado em 16/7/2008 